\section{Brain, Behavior and Evolution}

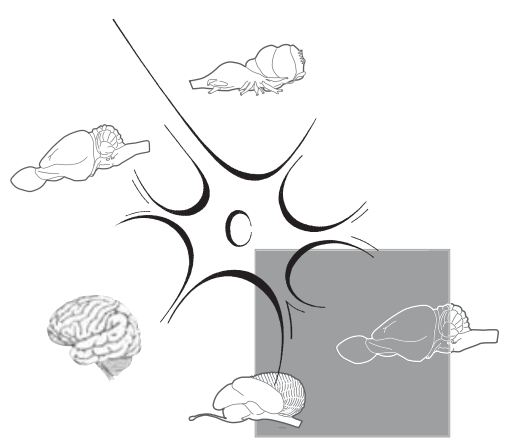

Antibodies are one of the most frequently used research tools in the comparative neurosciences. For an antibody to be useful as a molecular marker, it needs to specifically and selectively identify the object of interest. The validation process to determine if a marker is specific and selective is often laborious but is highly essential for establishing whether a new marker qualifies as a reliable tool.

In a critical review of our work, Balthazart and Ball [2014] argue that the microtubule-associated protein doublecortin (DCX) qualifies as a reliable marker for quantifying adult neurogenesis in canaries, despite observations that DCX is expressed in mature neurons in both neurogenic and nonneurogenic brain regions in canaries [Vellema et al., 2014] and mammals [e.g. Verwer et al., 2007; Cai et al., 2009; Klempin et al., 2011; Kremer et al., 2013].

\title{
What Makes a Marker a Good Marker?
}

\author{
Commentary on Balthazart J and Ball G (2014): Doublecortin is a highly \\ valuable endogenous marker of adult neurogenesis in canaries. Brain \\ Behav Evol 84:1-4
}

\author{
Michiel Vellema Meng-Ching Ko Carolina Frankl-Vilches \\ Manfred Gahr \\ Department of Behavioural Neurobiology, Max Planck Institute for Ornithology, \\ Seewiesen, Germany
}

\section{Validating DCX Expression against BrdU Labeling}

To validate if DCX truly predicts neuron recruitment throughout the canary brain, it should correlate to a high degree with established methods for studying neuron recruitment, such as labeling cells with the mitotic marker 5-bromo-2-deoxyuridine (BrdU). This is not the case, however, as we observed clear regional differences in the relationship between the two labeling methods in neurogenic and nonneurogenic brain areas in our study [Vellema et al., 2014: fig. 7B]. BrdU-labeling typifies the age of a cell, but gives no specific information about the cell's functional state. Balthazart and Ball [2014] correctly address the fact that the functional state of a neuron of a certain age can differ in different parts of the brain, potentially affecting the relationship between BrdUand DCX-labeling. Whether the large regional differences that we observed can be explained by the methodological differences between BrdU- and DCX-label- ing remains to be determined, but, so far, BrdU-labeling is one of the best methods that can be used in songbirds to validate DCX as a marker.

\section{Expression in Nonneurogenic Brain Regions}

The justification for using DCX as a marker for adult neurogenesis is, to a large extent, based on previous studies conducted in rodents, where the association between DCX expression and adult neurogenesis has been well established in the olfactory bulb and hippocampus. However, in what way the validation work in rodents applies to birds is difficult to judge, especially since the brain areas under investigation in birds are often in the pallium, a region of the brain where the association between DCX expression and neurogenesis is not very strong, even in mammals. Recent studies in rodents, but also in cats and primates (including humans), demonstrate the prominent presence of DCX expression

\section{KARGER}

E-Mail karger@karger.com www.karger.com/bbe
(2) 2014 S. Karger AG, Base

0006-8977/14/0841-0005\$39.50/0
Michiel Vellema

Department of Behavioural Neurobiology

Max Planck Institute for Ornithology

Eberhard-Gwinner-Strasse 6a, DE-82319 Seewiesen (Germany)

E-Mail vellema@orn.mpg.de 
in adult neurons and possibly mature astrocytes in pallial brain structures that are considered nonneurogenic [e.g. Verwer et al., 2007; Cai et al., 2009; Klempin et al., 2011]. These studies clearly illustrate that DCX is not a general marker for neurogenesis throughout the adult mammalian brain.

Similarly, we also observed DCX-labeling in mature neurons throughout the adult canary brain, including regions in the midbrain and hindbrain that have not previously been documented to recruit new neurons [Vellema et al., 2014]. The suggestion of Balthazart and Ball [2014] that these DCX-expressing mid- and hindbrain regions may constitute 'undiscovered' neurogenic brain areas seems unlikely, and over 30 years of neurogenesis research in the canary brain do not support it. It is possible to detect small numbers of BrdU-labeled cells in the songbird mid- and hindbrain after BrdU injection, but we have demonstrated before that these BrdU-labeled cells are not associated with neuron recruitment and are not immunoreactive for DCX or other neuronal markers [Vellema et al., 2010, 2014].

\section{Expression in Mature Neurons}

Although Balthazart and Ball [2014] acknowledge that DCX can be expressed by mature neurons, it is unclear why they believe that including these adult DCX-expressing neurons in their quantifications of young migrating neurons has no impact on the outcome of their quantifications. The suggestion that only very few mature neurons express DCX is misleading, and requires verification for each brain area under investigation. Klempin et al. [2011], for example, report strong DCX expression in the nonneurogenic piriform cortex, and Kremer et al. [2013] describe a substantial nonneurogenic pool of DCX protein in the adult rodent hippocampus. Similarly, we observed large numbers of DCX-expressing neurons in the nonneurogenic mid- and hindbrain regions of adult canaries [Vellema et al., 2014], a finding that to a large extent appears to be supported by the work of Boseret et al. [2007].

In songbirds, the observation that mature neurons express DCX in the mid- and hindbrain indicates that this could also be the case in the telencephalon, which most studies on neurogenesis have focused on in the past. To what extent DCX-expressing cells in the songbird telencephalon constitute mature neurons is more difficult to investigate, because a large part of the telencephalon continues to recruit adult-born neurons [Vellema et al., 2010]. Nevertheless, we observed subsets of DCX-expressing neurons in the canary telencephalon that were more than 60 days old, were colabeled with a marker for mature neurons, NeuN, or established connectivity with other brain areas [Vellema et al., 2014], suggesting that these neurons are not particularly young and undifferentiated. Of course, these neurons could have expressed DCX during migration, and retained some level of expression during postmigratory maturation. However, Merz and Lie [2013] report that the knockdown of DCX in the adult-born neurons of the mouse hippocampus does not alter the migration or morphological maturation of these neurons, leaving it open to speculation what functional relevance DCX expression could have for the development of adult-born neurons.

\section{Expression in Existing HVC Neuron Populations}

One of the song-controlling regions in the songbird brain, the nucleus HVC demonstrates a high degree of hormone-dependent morphological and cytoarchitectural plasticity, including an upregulation of DCX expression upon treatment with the hormone testosterone [Balthazart et al., 2008]. In order to conclude that changes in DCX expression after an experimental treatment, such as the application of testosterone, is caused by a change in neuron recruitment, as Balthazart et al. [2008] suggest, one first has to establish that the experimental treatment does not affect DCX expression in the adult neuron population in that brain region.

In a recent microarray study of the female canary HVC [M.-C.K., unpubl. data], we observed a 1.97-fold increase in DCX expression $8 \mathrm{~h}$ after testosterone treatment $(\mathrm{n}=5)$, and a 1.78 -fold increase in DCX expression 3 days after testosterone treatment $(n=6)$ compared to nontreated birds $(n=6)$. The microarray data analysis was performed (as described by C.F.-V. for male canaries: GEO accession No. GSM1254620) with a false discovery rate of $0 \%$. As it takes at least 3 days for newly generated neurons to migrate out of the lateral ventricle and into the HVC [Kirn et al.,
1999], these data suggest that testosterone treatment can directly affect DCX expression in local HVC neurons, independent of adult neurogenesis. This rapid upregulation of DCX expression could be mediated through putative estrogen and androgen receptor binding sites (so-called response elements) in the promoter and coding regions of the zebra finch $D C X$ gene (Genomatix Annotation ELDorado, Promoter ID: GXP_4805628; www.genomatix.de), which are also conserved in the corresponding canary sequence (Bioproject ID: PRJNA236325, PRJEB1766).

\section{Concluding Remarks}

There is little doubt that DCX plays an important role in neuronal plasticity in mammals, and this role may very well extend to songbirds. DCX does not specifically label young migrating neurons, however, and, as such, does not constitute a good marker for adult neurogenesis per se. In support of our conclusions, recent rodent studies also state that 'DCX is per se, no marker of neurogenesis' [Klempin et al., 2011] and suggest 'caution for the interpretation of such studies' [Kremer et al., 2013]. This does not mean that DCX can never be used to study neurogenesis. In the rodent olfactory bulb and hippocampus for example, DCX has been successfully used to measure adult neurogenesis even though its exact role is not clear. The successful use of DCX is highly region-specific, however, and in rodents does not seem to extend to other brain regions besides the olfactory bulb and hippocampus. Similarly, the correlation between DCX expression and adult neurogenesis in the songbird brain appears to differ greatly between brain areas. DCX may very well become a useful predictor for neuron recruitment in specific regions of the songbird brain, but this will require accurate validation for each brain region under investigation. 


\section{References}

Balthazart J, Ball G (2014): Doublecortin is a highly valuable endogenous marker of adult neurogenesis in canaries. Brain Behav Evol 84: $1-4$.

Balthazart J, Boseret G, Konkle AT, Hurley LL, Ball GF (2008): Doublecortin as a marker of adult neuroplasticity in the canary song control nucleus HVC. Eur J Neurosci 27:801-817.

Boseret G, Ball GF, Balthazart J (2007): The microtubule-associated protein doublecortin is broadly expressed in the telencephalon of adult canaries. J Chem Neuroanat 33:140154.

Cai Y, Xiong K, Chu Y, Luo DW, Luo XG, Yuan XY, Struble RG, Clough RW, Spencer DD, Williamson A, Kordower JH, Patrylo PR, Yan XX (2009): Doublecortin expression in adult cat and primate cerebral cortex relates to immature neurons that develop into GABAergic subgroups. Exp Neurol 216:342-356.
Kirn JR, Fishman Y, Sasportas K, Alvarez-Buylla A, Nottebohm F (1999): Fate of new neurons in adult canary high vocal center during the first 30 days after their formation. J Comp Neurol 411:487-494.

Klempin F, Kronenberg G, Cheung G, Kettenmann H, Kempermann G (2011): Properties of doublecortin-(DCX)-expressing cells in the piriform cortex compared to the neurogenic dentate gyrus of adult mice. PLoS One 6:e25760.

Kremer T, Jagasia R, Herrmann A, Matile H, Borroni E, Francis F, Kuhn HG, Czech C (2013): Analysis of adult neurogenesis: evidence for a prominent 'non-neurogenic' DCX-protein pool in rodent brain. PLoS One 8:e59269.
Merz K, Lie DC (2013): Evidence that doublecortin is dispensable for the development of adult born neurons in mice. PLoS One 8:e62693.

-Vellema M, Hertel M, Urbanus, SL, van der Linden A, Gahr M (2014): Evaluating the predictive value of doublecortin as a marker for adult neurogenesis in canaries (Serinus canaria). J Comp Neurol 522:1299-1315.

Vellema M, van der Linden A, Gahr M (2010): Area-specific migration and recruitment of new neurons in the adult songbird brain. J Comp Neurol 518:1442-1459.

Verwer RW, Sluiter AA, Balesar RA, Baayen JC, Noske DP, Dirven CM, Wouda J, van Dam AM, Lucassen PJ, Swaab DF (2007): Mature astrocytes in the adult human neocortex express the early neuronal marker doublecortin. Brain 130:3321-3335. 